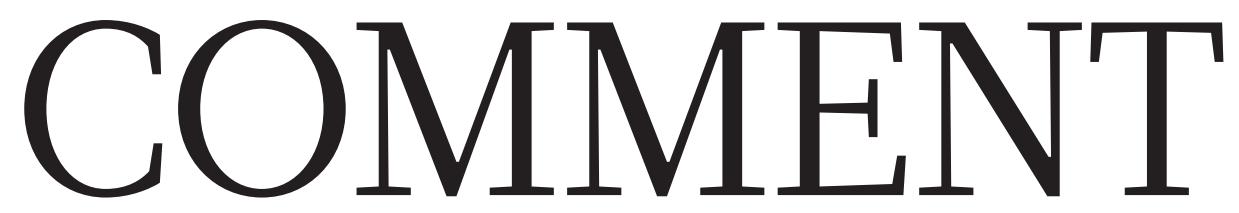

GEOLOGY From chemistry to conflict, the scrabble for rare metals $\mathbf{p . 1 4 2}$
SOCIETY Why water has always been centre stage in China's politics p.144
PUBLISHING A call to pay peer reviewers for their time and effort $\mathbf{p . 1 4 5}$
POLLUTION Beijing's week of blue skies - good policy or bad business? p.145

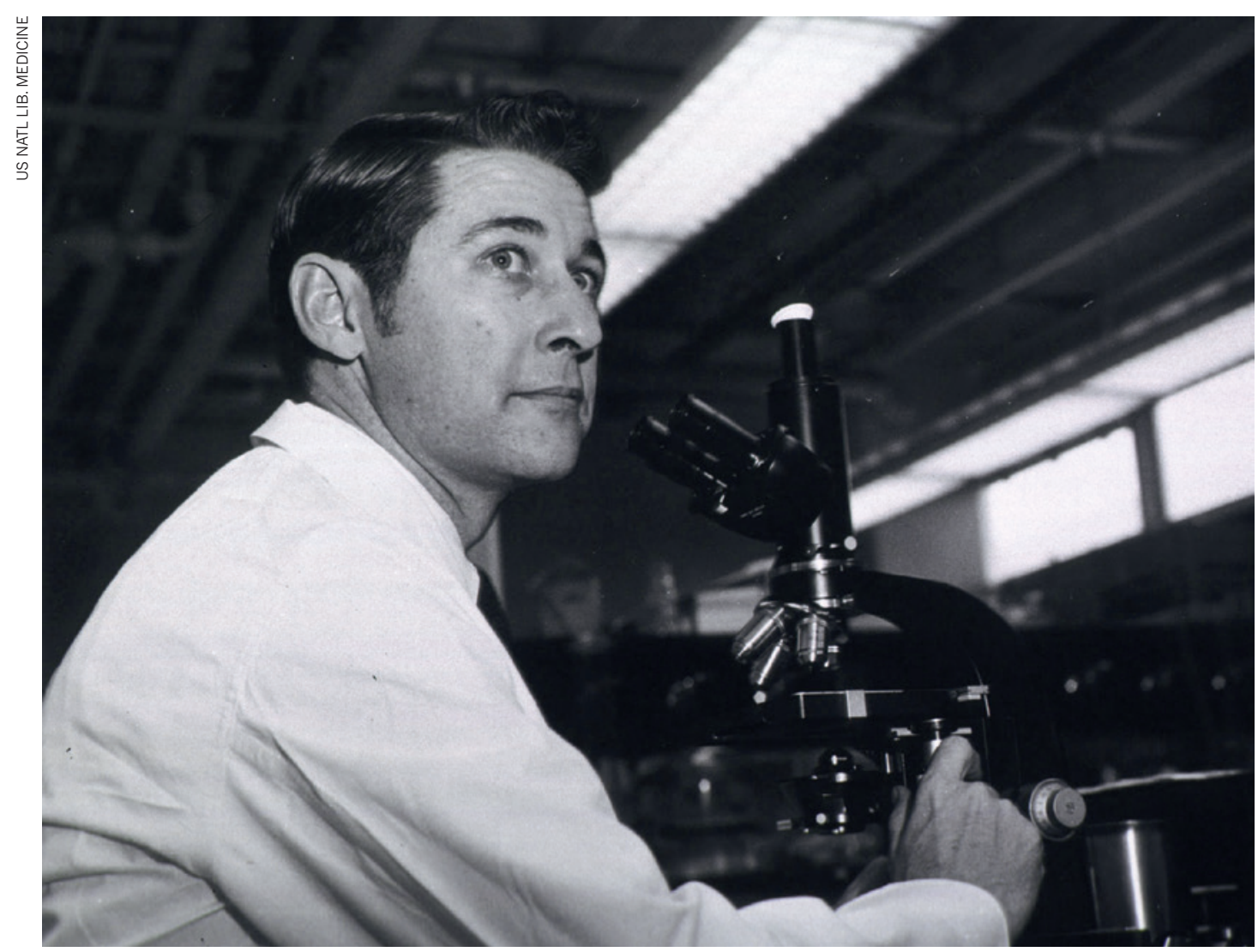

Max Cooper in Robert Good's lab at the University of Minnesota in the mid-1960s.

\title{
Fifty years of B lymphocytes
}

Alexander D. Gitlin and Michel C. Nussenzweig reflect on the discovery of two lineages of adaptive immune cells, and how it influenced vaccination, cancer therapy and the development of a class of antibody-based drugs.

$\mathrm{W}$

hen Max Dale Cooper joined Robert Good's laboratory at the University of Minnesota in Minneapolis in 1963, there were two camps in immunology. Neither was particularly fond of the other.

At the time, the central question in immunology was how vertebrates tailor their defences to bacteria and viruses, whose chemical structures show nearly unlimited diversity. Within two years of joining Good's laboratory, Cooper had made a discovery about the cells that accomplish this task - lymphocytes - that proved essential to cracking the mystery, and ultimately to unifying the camps of his field.

Fifty years ago this week, Good, Cooper and their colleague Raymond Peterson published a paper ${ }^{1}$ in this journal revealing that there are two types of lymphocyte. The insight shaped the course of modern immunology and influenced the study and care of immunodeficiency conditions, cancers of the immune system and the development of monoclonal antibodies - powerful research tools and therapeutics.

\section{CLONE WARFARE}

In the 1960s, one camp of immunologists dealt mainly in chemical terms and had by then made considerable progress. This group had discovered that antibody molecules are proteins with two binding sites that recognize an extraordinary range of foreign molecules (antigens), even synthetic ones; and that antibodies are composed of two heavy and $>$ 
$>$ two light chains, with amino acids that vary at one end (the $\mathrm{N}$ terminus) but that are constant at the other end (the $\mathrm{C}$ terminus).

The second camp dealt with immunology at the cellular and whole-organism level. Here, the clonal-selection theory, which hypothesized that lymphocytes are diverse and that each is unique, or clonal, was becoming increasingly accepted. Each cell carries a unique surface receptor that, when bound by antigen, triggers the proliferation of that clone. This theory was developed in the late 1950s by Frank Macfarlane Burnet at the Walter and Eliza Hall Institute (WEHI) of Medical Research in Melbourne, Australia, and David Talmage at the University of Chicago in Illinois ${ }^{2,3}$. It gave immunology a conceptual framework, yet proof of its existence and its workings remained elusive.

In 1961, Jacques Miller, also at the WEHI, demonstrated that a mouse with its thymus removed did not reject skin grafts from different strains of mice, as the animals normally would ${ }^{4}$. This suggested that the thymus was a crucial source of cells that mediate phenomena such as rejection, but his experiments were not universally accepted. At that time, antibodies were thought to derive only from lymphocytes (through plasma cells). But immunologists did not know whether and how the lymphocytes that produced antibodies and those involved in graft rejection were related.

It was in this context that Cooper, a paediatrician and clinical immunologist, made a set of clinical observations that were an early clue to the existence of two lymphocyte lineages ${ }^{5}$. People with Wiskott-Aldrich syndrome, a disorder linked to the X chromosome, developed rampant herpes viral lesions associated with defective immunity. Yet these people had high levels of antibodies. By contrast, boys with the inherited immunodeficiency X-linked agammaglobulinaemia could control such viral infections even though they lacked antibody responses. This hinted that antibody-producing lymphocytes and thymus-derived lymphocytes that reject grafts (as in Miller's mouse experiments) might be two different things.

\section{THE KEY EXPERIMENT}

Cooper was one of the few immunologists who found clues to this paradox in a 1956 Poultry Science report ${ }^{6}$. It recounted an 'accidental' finding about the bursa of Fabricius, an organ unique to birds that at the time was thought to have a hormonal role in growth and development. The authors, Bruce Glick and his colleagues, wrote of their "suspicion regarding the importance of the bursa in antibody production". To study the role of the organ, Glick and his colleagues used chickens that had had their bursae removed for an unrelated experiment. To the researchers' surprise, these chickens showed

\section{TWO LINES OF ATTACK}

In mammals, the haematopoietic (or blood-forming) tissues serve the same immune function as the bursa in chickens.

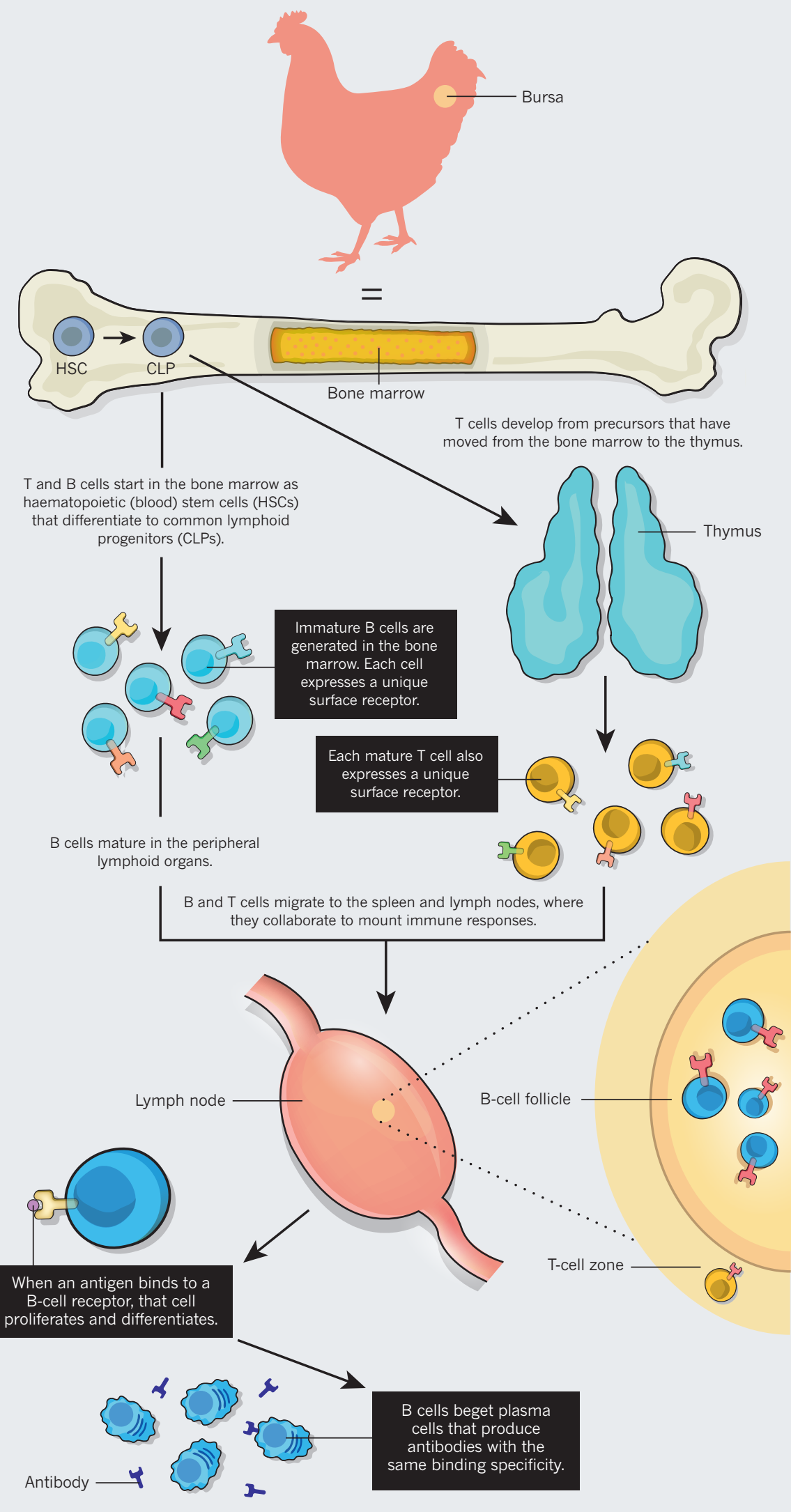


remarkably poor antibody production.

Good and Cooper decided to revisit the role of the bursa and the thymus in chickens. Up until that point, organremoval studies in chickens had yielded conflicting results. Cooper reasoned that these differences could have arisen because some chickens might have developed immune cells before their organs were taken out ${ }^{5}$. His solution was to irradiate hatchlings a day after removing the organs, which eliminated any cells generated by a chick's thymus or bursa before hatching. These chicks would thus reveal the roles that these organs have in immune development.

The result, published in Nature on 9 January 1965, was spectacular ${ }^{1}$. Irradiated chickens with no bursae produced no antibodies when injected with either bovine serum albumin, a protein derived from cattle, or the bacterium Brucella abortus. Serum from the birds completely lacked the major antibody classes. Yet the region of the white pulp in the spleen that is dependent on the thymus was intact. The dramatic phenotype was highly reminiscent of that of patients with X-linked agammaglobulinaemia.

The next year, Cooper and his colleagues extended their seminal study in an important paper published in the Journal of Experimental Medicine ${ }^{7}$. They used their irradiated chickens - without thymus and bursa - to elucidate the different functions of the immune cells produced by the two organs. They found that B (bursa-derived) cells are required for antibody responses, whereas $\mathrm{T}$ (thymus-derived) cells mediate delayedtype hypersensitivity reactions, graft-versushost rejection and skin-graft rejection - all functions of cellular immunity.

The explanatory power of the twolymphocyte model for immunodeficiency diseases was immense $^{5}$. Because people with X-linked agammaglobulinaemia are deficient in antibody production but not in cellular immunity, their disease was proba-

\section{"Understanding" of the divergent lymphocyte lineages started to change the treatment of leukaemias and lymphomas."}

bly due to a deficiency in B-cell development only. By contrast, the Swiss-type agammaglobulinaemia, in which both cellular and antibody-based immunity are severely compromised, was likely to be caused by a deficiency in a precursor cell common to both $\mathrm{T}$ and $\mathrm{B}$ lineages. Not surprisingly, clinicians were more receptive to Cooper's findings than were basic immunologists.

Next, the most important quest for Cooper was to find an organ in mammals equivalent to the bursa. Without it, the relevance and generality of his findings remained

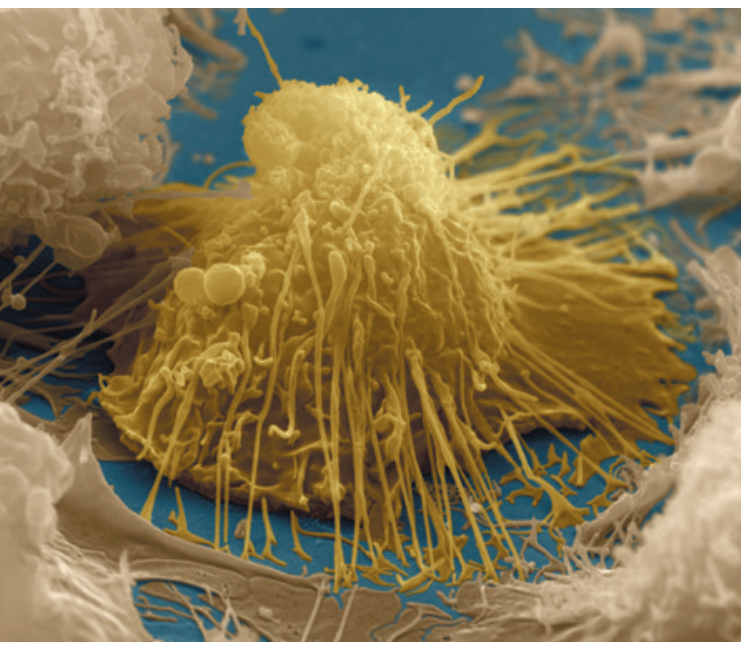

A coloured scanning electron micrograph of a B lymphocyte.

controversial for nearly another decade. Scientists would often ask Cooper, "Where is the bursa equivalent this year, Max?"

Finding the equivalent organ to the bursa in mammals proved difficult. Initially, Cooper and his colleagues suspected that intestinal tissue was the source of B cells; they expended enormous effort on this dead end ${ }^{5}$.

The answer finally came in 1974, when Cooper, together with Martin Raff and John Owen at University College London, cultured mouse fetal liver cells from day 14 of gestation. After four to seven days in culture, B cells were generated ${ }^{8}$. At the same time, groups led by Gustav Nossal at the WEHI and Pierre Vassalli at the University of Geneva, Switzerland, made similar findings, using mouse bone marrow ${ }^{5}$. In other words, the haematopoietic, or bloodforming, tissues serve the same function in mammals as the bursa in chickens (see 'Two lines of attack').

By the late 1970s, this understanding of the divergent lymphocyte lineages started to change the treatment of leukaemias and lymphomas. The cells of origin of these tumours could now be used to classify the cancers and to tailor therapies. Thus, acute lymphoblastic leukaemias could be B-cell- or T-cell-derived or neither; non-Hodgkin's and Burkitt's lymphomas are B-cell-derived. The effectiveness of various therapies for these cancers often dovetailed with their classification.

\section{DRUGS AND VACCINES}

Among the biggest impacts of B-cell biology was the invention of hybridomas - immortal antibody-producing cell lines. In 1975, Georges Köhler and César Milstein at the MRC Laboratory of Molecular Biology in Cambridge, UK, reported that they had fused B cells with a myeloma cell line ${ }^{9}$. The resulting hybrid cell continuously produced its specific antibody. This was the birth of monoclonal-antibody technology, garnering Köhler, Milstein and Niels Jerne the 1984
Nobel Prize in Physiology or Medicine.

The effect of this accomplishment is difficult to overstate. In the ensuing years, monoclonal antibodies permeated all of experimental biology. These molecules are potent and specific reagents that can be used to identify, isolate and perturb nearly any molecule or cell of interest. Clinically, monoclonal antibodies have become some of the most powerful diagnostics and therapeutics.

Cooper's discovery also set the stage for answering the fundamental question of clonal-selection theory: how is clonal diversity generated? The elegant molecular solution to this problem was elucidated ${ }^{10}$ by Susumu Tonegawa in 1976. B cells assemble a diverse set of antibodies by combining a set of three types of gene segment from a large pool of potential segments.

Finally, the antibodies for which so much had been elucidated at the chemical level were now understood at the genetic, cellular and organismal levels. By the mid-1980s, the clonal nature of the T-cell system had also been explained. Through their discovery of the $\mathrm{B}$ and $\mathrm{T}$ cell systems, Cooper and his colleagues set in motion a series of landmark findings that united the chemical and cellular camps of the discipline.

Key questions remain in B-cell biology. In particular, there are major unmet needs in vaccine development for HIV, influenza and many other infectious agents. Understanding how B cells are selected to differentiate into long-lived cells that provide protection from infection will guide us where empirical approaches have failed.

As these discoveries continue to affect human health, it remains important to remember their origins in an experiment performed 50 years ago, by Cooper, in chickens.

Alexander D. Gitlin is an MD-PhD student in the Weill Cornell/Rockefeller/SloanKettering Tri-Institutional programme in New York City, New York, USA. Michel C. Nussenzweig is a professor and HHMI investigator at Rockefeller University in New York, New York, USA. e-mail:nussen@mail.rockefeller.edu

1. Cooper, M. D., Peterson, R. D. A. \& Good, R. A. Nature 205, 143-146 (1965).

2. Burnet, F. M. The Clonal Selection Theory of Acquired Immunity (Vanderbilt Univ. Press, 1959).

3. Talmage, D. W. Science 129, 1643-1648 (1959).

4. Miller, J. F. A. P. Immunol. Rev. 185, 7-14 (2002).

5. Cooper, M. D. A. Ann. Rev. Immunol. 28, 1-19 (2009)

6. Glick, B., Chang, T. S. \& Jaap, R. G. Poultry Sci. 35, 224-225 (1956).

7. Cooper, M. D., Raymond, D. A., Peterson, R. D., South, M. A. \& Good, R. A. J. Exp. Med. 123, 75-102 (1966).

8. Owen, J. J. T., Cooper, M. D. \& Raff, M. C. Nature 249, 361-363 (1974)

9. Köhler, G. \& Milstein, C. Nature 256, 495-497 (1975).

10. Hozumi, N. \& Tonegawa, S. Proc. Natl Acad. Sci. USA 73, 3628-3632 (1976). 